\title{
Controle e progresso temporal da ferrugem asiática da soja sob controle alternativo em campo
}

\author{
Renata Moreschi Mesquini ${ }^{1}$, Kátia Regina Freitas Schwan-Estrada ${ }^{1 *}$, Rafael Augusto Vieira ${ }^{1}$, Jefferson Fernandes \\ Nascimento ${ }^{2}$.
}

${ }^{1}$ Universidade Estadual de Maringá, Departamento de Agronomia, Av. Colombo no 5790, CEP 87020-900, Maringá, Paraná, Brasil. ${ }^{2}$ Universidade Federal de Roraima, Departamento de Fitotecnia, BR 174, Km-13 - Campus do Cauamé, CEP 69310-270, Boa Vista, Roraima, Brasil. Autor para correspondência: Kátia Regina Freitas Schwan-estrada (schwan@wnet.com.br)

Data de chegada: 09/09/2008. Aceito para publicação em: 10/07/2010.

\section{RESUMO}

Mesquini, R.M., Schwan-estrada, K. R. F., Vieira, R. A., Nascimento, J. F. Controle e progresso temporal da ferrugem asiática da soja sob controle alternativo em campo. Summa Phytopathologica, v.37, n.1, p.24-29, 2011.

O objetivo deste trabalho foi avaliar o controle e o progresso temporal da ferrugem asiática da soja, causada por Phakopsora pachyrhizi, sob manejo com tratamentos alternativos. Para isso, implementou-se um ensaio em delineamento de blocos completos com tratamentos ao acaso, com 4 repetições, em Itambé-PR, durante a safra 2007/2008. Os tratamentos alternativos foram: biomassa cítrica, extrato bruto e óleo essencial de Eucalyptus citriodora e grãos de kefir. Avaliou-se também o controle químico com azoxistrobina + ciproconazole + adjuvante $0,5 \mathrm{v} / \mathrm{v}$ e a testemunha. Para comparação dos tratamentos utilizou-se a severidade da doença (em cinco avaliações), a área abaixo da curva de progresso da doença (AACPD), a taxa de progresso da doença, a produtividade e o peso de mil grãos. Foram constatadas diferenças significativas $(\mathrm{Pd}$ ”0,05) para as avaliações de severidade, para AACPD e para a taxa de progresso da doença. De modo geral, dentre os tratamentos alternativos, a biomassa cítrica e os grãos de kefir apresentaram os maiores índices de controle e menores taxas de progresso da doença, superando os tratamentos com extrato bruto e óleo essencial de E. citriodora. Porém, o tratamento com azoxistrobina + ciproconazole foi mais eficiente para controle e proporcionou as menores taxas de progresso quando comparado aos tratamentos alternativos.

Palavras-chave adicionais: Glycine max; Phakopsora pachyrhizi; Eucalyptus citriodora

\section{ABSTRACT}

Mesquini, R.M., Schwan-estrada, K. R. F., Vieira, R. A., Nascimento, J. F. Control and temporal progress of Asian soybean rust under alternative control in the field. Summa Phytopathologica, v.37, n.1, p.24-29, 2011.

The aim of this work was to evaluate the control and the temporal progress of Asian soybean rust, caused by Phakopsora pachyrhizi, under management with alternative treatments. Thus, an experiment was carried out under a randomized block design, in Itambé, municipality, Paraná State, Brazil, during the cropping season 2007/2008. The alternative treatments were: citric biomass, crude extract and essential oil of Eucalyptus citriodora and kefir grains. Chemical control using azoxystrobin + cyproconazol + adjuvant $0,5 \mathrm{v} / \mathrm{v}$ was also evaluated. Disease severity (in five evaluations), area under the disease progress curve (AUDPC), disease progress rate, productivity and 1000 grain weight were used for comparison among treatments. Significant differences (Pd" 0,05$)$ were observed for severity, AUDPC and disease progress rate. In general, citric biomass and kefir grains had the highest control indexes and lower disease progression rates among the alternative treatments showing to be superior to the treatments with crude extract and essential oil of E. citriodora. However, azoxystrobin + cyproconazol were more efficient to control the disease and led to the lowest progress rates, relative to the alternative treatments.

Keywords: Glycine max; Phakopsora pachyrhizi ; Eucalyptus citriodora

Após ter sido relatada na safra 2000/2001 no Paraná, a ferrugem asiática, causada por Phakopsora pachyrhizi Sydow \& P. Sydow tornou-se a principal doença da cultura da soja, causando danos ao rendimento de grãos devido à desfolha precoce. Na safra 2006/ 2007, os danos provocados pela doença foram de aproximadamente 2,67 milhões de toneladas de grãos (5).

Em termos de produção mundial, o Brasil ocupa a segunda colocação entre os produtores mundiais de soja, vindo após os Estados Unidos. As mais importantes áreas de cultivo localizamse nos Estados do Mato Grosso, Paraná e Rio Grande do Sul (9). De modo geral, o menor custo de produção e o preço de venda superior ao da soja convencional, são os fatores que motivam a produção orgânica, tanto para atender o mercado externo, para consumo in natura, como para o mercado interno, na obtenção de produtos orgânicos. Entretanto, para o controle da ferrugem asiática, a medida de controle mais amplamente empregada é o uso de fungicidas, já que, atualmente, não há genótipos resistentes disponíveis aos produtores $(12,17)$.

Bettiol (2) apontam o uso indiscriminado de produtos químicos como fator para a redução da biodiversidade e para contaminações do ambiente, empregada principalmente no controle biológico natural de pragas e doenças. A adoção contínua do controle químico 
pode acarretar o surgimento de patógenos resistentes aos produtos utilizados (7) o que poderia ocorrer com P. pachyrhizi uma vez que não existem produtos diversificados para o seu controle.

Diante das escassas informações com relação ao controle da ferrugem asiática em sistemas que não utilizam agroquímicos, do apelo ambiental crescente e, considerando os resultados promissores no uso de óleos essenciais e extratos de plantas medicinais para o controle de doenças de plantas (15), este trabalho teve como objetivo avaliar o controle e o progresso da ferrugem asiática, em condições de campo, quando submetida aos tratamentos com produtos alternativos.

\section{MATERIAL E MÉTODOS}

Foram avaliados os seguintes tratamentos: i) óleo essencial de Eucalyptus citriodora: obtido por sistema de arraste a vapor no Laboratório de Plantas Medicinais da Universidade Estadual de Maringá, sintetizado na proporção de 3,0 kg de folhas frescas para $8,0 \mathrm{~mL}$ de óleo essencial e aplicado na dose de $0,5 \%$ de volume do produto no volume da calda; ii) extrato bruto de E. citriodora: obtido de folhas frescas, coletadas e trituradas em liquidificador com água destilada e aplicado na dose de 5,0\% de peso do produto no volume de calda; iii) biomassa cítrica: utilizando o produto comercial Ecolife ${ }^{\circledR}$ na dosagem de 1,0 litro ha ${ }^{-1}$; iv) grãos de Kefir: cultivados em água e açúcar mascavo e supridos em alimentação a cada 24 horas, autoclavado por 20 minutos à temperatura de 120 ${ }^{\circ} \mathrm{C}$ e à pressão de 1 atmosfera, e aplicados na dosagem de $10,0 \%$ de peso no volume de calda.

O ensaio foi instalado no município de Itambé-PR, a 23³9' de latitude Sul, $51^{\circ} 59^{\prime}$ de longitude Oeste e $428 \mathrm{~m}$ de altitude, com semeadura do cultivar de soja BRS 184 em 21 de outubro de 2007. O delineamento experimental foi de blocos completos com tratamentos ao acaso, com quatro repetições. As unidades experimentais foram constituídas de 5 linhas de semeadura espaçadas em 0,45 metros, perfazendo uma área de 11,25 $\mathrm{m}^{2}$. Foram consideradas como parcela útil as três linhas centrais, descartando 0,5 metros em cada extremidade, totalizando-se $5,75 \mathrm{~m}^{2}$. Os tratamentos consistiram, além dos quatro produtos alternativos supracitados, da testemunha - sem qualquer aplicação - e do controle químico com azoxistrobina + ciproconazole, na dosagem de 0,3 litros $\mathrm{ha}^{-1}$, acrescido do adjuvante recomendado, a $5 \%$ volume do produto no volume da calda. Os tratamentos alternativos foram aplicados por três vezes (nos estádios $\mathrm{R}_{1}, \mathrm{R}_{2}$ e $\mathrm{R}_{3}$ ) e de forma preventiva. Para o tratamento com azoxistrobina + ciproconazole, foi realizada apenas uma aplicação, também preventiva e em R3. Todas as aplicações foram realizadas usando um pulverizador costal manual e volume de calda de 200 litros $\mathrm{ha}^{-1}$. Os tratos culturais para a área do ensaio foram realizados conforme a necessidade e seguindo as recomendações para a cultura da soja.

Para comparação do controle e do progresso da doença nos tratamentos, foram avaliadas as seguintes variáveis - resposta: a) severidade da doença: em cinco avaliações de quantificação, tomandose ao acaso 10 plantas por parcela e atribuindo valores de severidade nos folíolos obtidos nos terços superior, médio e inferior. Para auxílio na estimativa da severidade foi utilizada a escala diagramática proposta por Godoy (8); b) área abaixo da curva de progresso da doença (AACPD): estimada conforme a equação apresentada por Campbell \& Madden (3) e usando os valores de severidade das cinco avaliações; c) taxa de progresso da doença: estimada nos diferentes tratamentos após a escolha do modelo matemático de melhor ajuste às curvas de progresso da doença, tomando como critérios para a escolha do modelo o coeficiente de determinação dos dados não linearizados $\left(\mathrm{R}^{* 2}\right)$ e a aleatoriedade dos resíduos plotados no tempo $(3,1)$; d) produtividade de grãos: por pesagem dos grãos da parcela útil, colhidos manualmente, corrigidos para a umidade de $13 \%$ e, transformados para $\mathrm{kg} \mathrm{ha}^{-1}$; e) peso de mil grãos: tomando por amostragem de grãos de cada parcela, expresso em gramas.

Os dados obtidos foram submetidos ao teste de Bartlett para verificar a homogeneidade das variâncias e o método de Kolmogorov-Smirnov para atestar a distribuição dos dados e dos erros, pressupostos para a análise de variância. Para atender aos pressupostos, os dados de severidade na segunda, terceira e quarta avaliação e os valores de AACPD foram transformados para ( $\mathrm{x})^{0,5}$. Posteriormente, aplicou-se à análise de variância (ANOVA) e, havendo significância a $5 \%$ de probabilidade pelo teste $\mathrm{F}$, compararam-se as médias dos tratamentos por meio do teste de agrupamento de Scott-Knott, a 5\% de probabilidade. Essas análises estatísticas foram realizadas por meio do programa SISVAR (6).

\section{RESULTADOS E DISCUSSÃO}

A análise de variância para os dados de severidade em cada avaliação constatou diferenças significativas entre os tratamentos em todas as avaliações realizadas (Tabela 1). Na primeira avaliação, aos 103 dias após a emergência da cultura, os quatro tratamentos alternativos e o fungicida apresentaram controle semelhante entre si, e superior quando comparados à testemunha. Este fato se deve a pressão da doença neste estádio da cultura, havendo a detecção de sintoma apenas a partir do estádio R5. Considerando a severidade constatada para os 108 dias após o plantio, o extrato bruto de $E$. citriodora foi menos eficiente para controlar a doença do que os demais tratamentos alternativos e o fungicida, com $45 \%$ de controle em relação à testemunha, sendo que na mesma situação os tratamentos com biomassa cítrica e fungicida controlaram $87 \%$ e $96 \%$ respectivamente. Na avaliação referente aos 113 dias após a semeadura, não houve diferença significativa entre os tratamentos com óleo essencial de E. citriodora, biomassa cítrica, grãos de kefir e fungicida. Aos 118 dias o fungicida foi superior ao óleo essencial e aos grãos de kefir, e não diferiu da biomassa cítrica, que obteve $90 \%$ de controle da doença em relação à testemunha.

O produto a base de biomassa cítrica, denominado Ecolife ${ }^{\circledR}$, possui em sua constituição bioflavonóides cítricos, ácido ascórbico e fitoalexinas capazes de ter efeito protetor e/ou curativo em alguns patossistemas. O efeito desse composto já foi verificado no patossistema Hemileia vastatrix em cafeeiro, reduzindo a severidade da ferrugem em até $73 \%$, evidenciando o efeito protetor desse produto (4). Os grãos de kefir apresentam em sua microflora cinco gêneros de microrganismos, incluindo lactobacilos e leveduras, que podem apresentar capacidade de sintetizar compostos antibióticos, habilidade de competição por espaço e nutrientes. Piccinin et al. (11) utilizaram a levedura Saccharomyces cerevisiae no controle da antracnose e da mancha foliar do sorgo e em condições de campo. As aplicações semanais dessa levedura reduziram a velocidade de progresso da doença em magnitude semelhante ao tratamento com fungicida (propiconazole 2,5mL/L), demonstrando um desempenho satisfatório.

Para a avaliação realizada aos 123 dias após a semeadura, os tratamentos com óleo essencial de E. citriodora, biomassa cítrica e grãos de kefir apresentaram índices 61, 77 e $75 \%$ de controle, respectivamente, sendo, superados pelo fungicida, que apresentou $99 \%$ de controle da doença. O tratamento com óleo essencial de $E$. 
Tabela 1. Estimativas médias de severidade (\%) da ferrugem asiática sob os diferentes trata men mentos aplicados na cultivar de soja BRS 184. ItambéPR, safra 2007/2008.

\begin{tabular}{lccccc}
\hline \multirow{2}{*}{ Tratamento } & \multicolumn{3}{c}{ Dias após a semeadura } \\
\cline { 2 - 6 } & \multicolumn{1}{c}{103} & 108 & 113 & 118 & 123 \\
\cline { 2 - 6 } & Severidade & Severidade & Severidade & Severidade & Severidade \\
\hline \multirow{2}{*}{ azoxistrobina + ciproconazole } & $0,12 \mathrm{a}$ & $0,12 \mathrm{a}$ & $0,13 \mathrm{a}$ & $0,24 \mathrm{a}$ & $0,43 \mathrm{a}$ \\
OE E. citriodora & $0,25 \mathrm{~b}$ & $0,58 \mathrm{a}$ & $1,30 \mathrm{a}$ & $4,94 \mathrm{~b}$ & $15,27 \mathrm{~b}$ \\
Biomassa cítrica & $0,27 \mathrm{~b}$ & $0,38 \mathrm{a}$ & $0,60 \mathrm{a}$ & $1,45 \mathrm{a}$ & $8,93 \mathrm{~b}$ \\
Grãos de Kefir & $0,33 \mathrm{~b}$ & $0,52 \mathrm{a}$ & $0,89 \mathrm{a}$ & $2,84 \mathrm{~b}$ & $9,68 \mathrm{~b}$ \\
Extrato bruto de E. citriodora & $0,29 \mathrm{~b}$ & $1,59 \mathrm{~b}$ & $3,12 \mathrm{~b}$ & $12,98 \mathrm{c}$ & $22,60 \mathrm{c}$ \\
Testemunha & $0,42 \mathrm{c}$ & $2,89 \mathrm{~b}$ & $7,78 \mathrm{c}$ & $14,02 \mathrm{c}$ & $39,14 \mathrm{~d}$ \\
\hline P $>\mathrm{F}^{2}$ & 0,0005 & 0,0012 & $<0,0001$ & $<0,0001$ & $<0,0001$ \\
CV $(\%)$ & 24,11 & 39,48 & 28,89 & 27,22 & 26,15 \\
\hline
\end{tabular}

1 Médias nas colunas seguidas pela mesma letra não diferem estatisticamente pelo teste de Scott-Knott a 5\% de probabilidade. 2 Probabilidade mínima de significância para o efeito de tratamento, pelo teste $\mathrm{F}$ da ANOVA.

citriodora aparentou uma redução na sua eficiência quando comparado com a avaliação anterior, aos 113 dias. Provavelmente algum fator pode ter influenciado a ação desse produto, como uma possível volatilização quando aplicado em campo. Medice et al. (10) verificaram que o óleo essencial de E. citriodora foi capaz de reduzir $53,18 \%$ a severidade da ferrugem asiática da soja, em casa de vegetação. Santos et al. (14) estudaram a eficiência de extratos aquosos de casca de frutos de café (CFC), extratos de folhas de café com ferrugem (EDIF) e biomassa cítrica, no controle da ferrugem do cafeeiro. A incidência da ferrugem nos cafeeiros pulverizados com CFC e EFID foi menor do que na testemunha pulverizada com água e semelhante à biomassa cítrica. O tratamento CFC proporcionou área abaixo da curva de progresso da severidade $49 \%$ inferior ao observado na testemunha, enquanto EFID reduziram a severidade em $31 \%$.

Com base na AACPD (Tabela 2), os tratamentos alternativos com óleo essencial e extrato bruto de E. citriodora apresentaram controle ineficiente, porém, ainda superior à testemunha. $\mathrm{Na}$ agricultura orgânica, o uso de produtos naturais que sejam eficientes em reduzir a intensidade de doenças em qualquer percentual devem serem vistos com interesse. Essa redução resultou em menor área abaixo da curva de progresso das plantas pulverizadas com biomassa cítrica e grãos de kefir, denotando menor intensidade da doença devido ao controle mais eficiente. Entretanto, vale ressaltar que todos os produtos alternativos, bem como a testemunha, apresentaram valores de AACPD superiores ao expressado no tratamento fungicida, que apresentou o melhor controle (Tabela 2).

As curvas de progresso da ferrugem asiática nos diferentes tratamentos foram também ajustadas aos modelos monomolecular, logístico e Gompertz, possibilitando a comparação por meio da taxa de progresso da doença, estimada conforme o modelo escolhido. O resumo da análise de regressão linear simples pode ser observado na Tabela 3. Realizou-se o ajuste por meio do módulo do programa SAS (13). De acordo com os resultados, pôde se constatar que, apesar dos diferentes níveis de intensidade nos tratamentos, o modelo logístico apresentou os maiores valores de $\mathrm{R}^{* 2}$ e a maior aleatoriedade na plotagem dos resíduos pelo tempo, indicando o melhor ajuste para os tratamentos. A escolha do modelo logístico para o patossistema $P$. pachyrhizi x soja, apresentada neste trabalho, está em consonância com a escolha feita por Tsukahara et al. (16),

Tabela 2. Área abaixo da curva de progresso de doença (AACPD), taxa de progresso da doença, produtividade e peso de 1000 sementes para os diferentes tratamentos aplicados na cultivar de soja BRS 184. Itambé-PR, safra 2007/2008.

\begin{tabular}{lcccc}
\hline Tratamento & AACPD & Taxa de progresso & PMG $^{2}$ & Produtividade (sacas ha $^{-1}$ ) \\
\hline azoxistrobina+ciproconazole & $3,80 \mathrm{a}^{1}$ & $0,066 \mathrm{a}$ & 163,67 & 56 \\
OE E. citrodora & $91,17 \mathrm{c}$ & $0,212 \mathrm{~b}$ & 157,13 & 52 \\
Biomassa cítrica & $36,99 \mathrm{~b}$ & $0,170 \mathrm{~b}$ & 158,67 & 55 \\
Grãos de Kefir & $44,32 \mathrm{~b}$ & $0,170 \mathrm{~b}$ & 162,96 & 48 \\
Extrato bruto de E.citriodora & $127,29 \mathrm{c}$ & $0,232 \mathrm{c}$ & 159,54 & 52 \\
Testemunha & $222,31 \mathrm{~d}$ & $0,238 \mathrm{c}$ & 154,62 & 45 \\
\hline $\mathrm{P}>\mathrm{F}^{2}$ & $<0,0001$ & $<0,0001$ & 0,1249 & 0,0809 \\
$\mathrm{CV}(\%)$ & 15,41 & 11,28 & 10,82 & 3,78 \\
\hline
\end{tabular}

1 Médias nas colunas seguidas pela mesma letra não diferem estatisticamente pelo teste de Scott-Knott a 5\% de probabilidade. 2 Probabilidade mínima de significância para o efeito de tratamento, pelo teste $\mathrm{F}$ da ANOVA. 

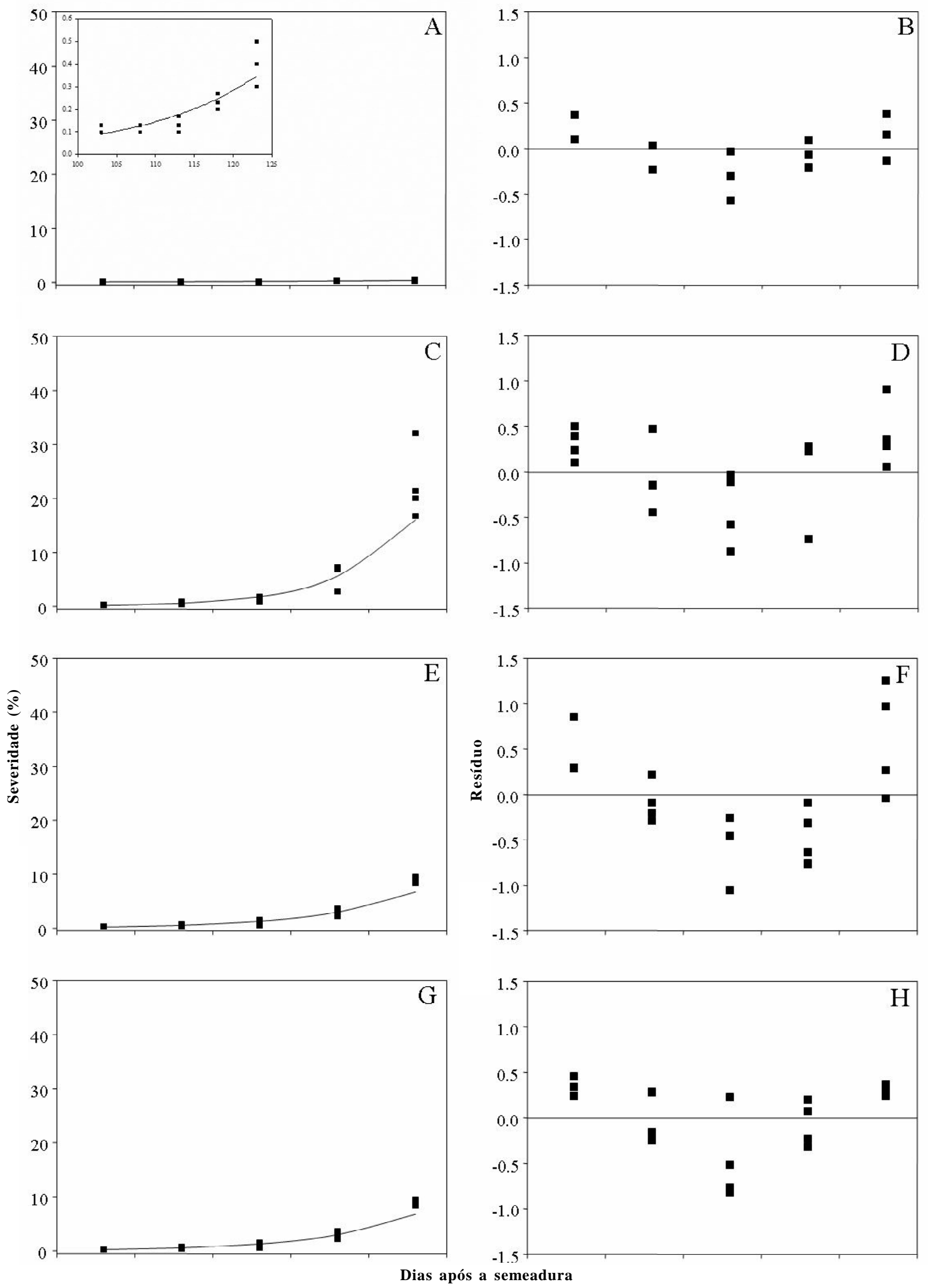

continua... 

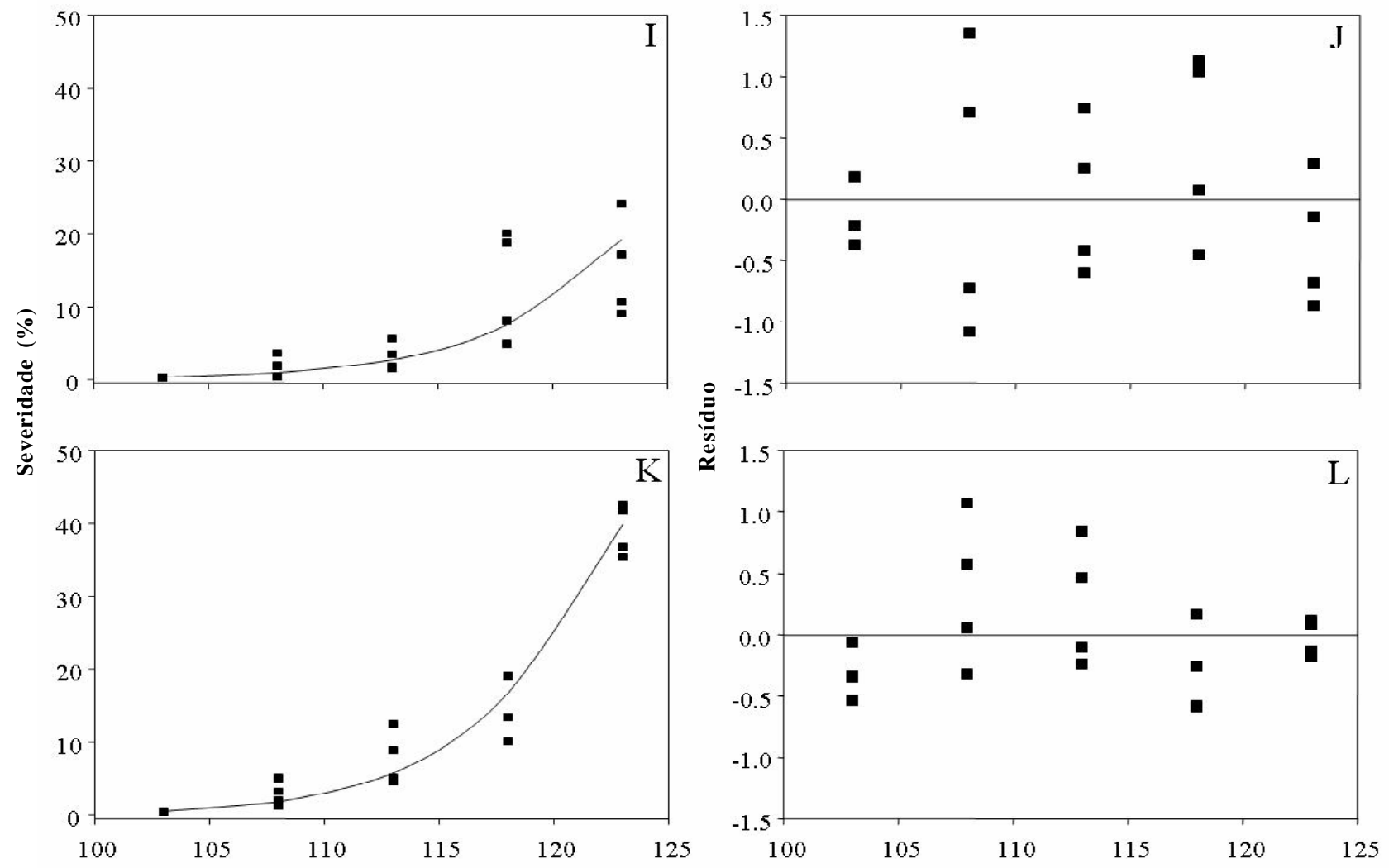

Figura 1. Dados reais de progresso da severidade de ferrugem asiática - plots - e a curva predita pelo modelo logístico - linhas cheias - (à esquerda); e plotagem dos resíduos do ajuste do modelo logístico pelo tempo (à direita). Azoxistrobina + ciproconazole (A e B), óleo essencial de E. citriodora (C e D), biomassa cítrica (E e F), grãos de kefir ( $\mathrm{G}$ e H), extrato bruto de E. citriodora (I e J) e testemunha (K e L).

Tabela 3. Resumo da análise de regressão linear usada para o ajuste dos modelos monomolecular, logístico e de Gompertz à curva de progresso da ferrugem asiática submetida aos tratamentos avaliados.

\begin{tabular}{|c|c|c|c|c|}
\hline Tratamento & Modelo & $\mathrm{R}^{2^{*}(1)}$ & Coeficiente linear da reta $\left(\beta_{0}\right)$ & Coeficiente angular da reta $\left(\beta_{1}\right)$ \\
\hline Azoxistrobina + ciproconazole & Logístico & 0,81 & $-7,744$ & 0,066 \\
\hline \multirow[t]{2}{*}{ Biomassa cítrica } & Monomolecular & 0,46 & $-0,062$ & 0,004 \\
\hline & Logístico & 0,71 & $-8,243$ & 0,170 \\
\hline \multirow[t]{3}{*}{ Grãos de kefir } & Monomolecular & 0,71 & $-0,057$ & 0,004 \\
\hline & Logístico & 0,97 & $-7,931$ & 0,170 \\
\hline & Gompertz & 0,93 & $-2,317$ & 0,042 \\
\hline \multirow[t]{2}{*}{ Óleo essencial de E.citriodora } & Monomolecular & 0,61 & $-0,119$ & 0,009 \\
\hline & Logístico & 0,57 & $-8,038$ & 0,212 \\
\hline Extrato bruto de E.citriodora & Gompertz & 0,84 & $-2,676$ & 0,066 \\
\hline \multirow[t]{3}{*}{ Testemunha } & Monomolecular & 0,73 & $-0,313$ & 0,022 \\
\hline & Logístico & 0,96 & $-7,795$ & 0,238 \\
\hline & Gompertz & 0,92 & $-2,654$ & 0,082 \\
\hline
\end{tabular}

$1 \mathrm{R}^{2 *}$ : Coeficiente de determinação dos dados não linearizados. 
que estudaram o progresso da doença em duas regiões do Estado do Paraná. As curvas de progresso da doença nos diferentes tratamentos avaliados, assim como as curvas preditas pelo modelo logístico e a plotagem dos resíduos do ajuste deste modelo são apresentadas na Figura 1.

Após a escolha do modelo logístico, a taxa de progresso da doença foi estimada, para cada repetição dos tratamentos, por: (1/ $t)\left(\ln (x /(1-x))-\left(\ln \left(x_{0} /\left(1-x_{0}\right)\right)\right)\right.$, onde: $t=$ tempo de duração da epidemia; $x=$ severidade final da doença; e $x_{0}=$ severidade inicial da doença ou inóculo inicial. A análise de variância para os valores estimados de taxa indicaram diferenças significativas (Pd"0,05) entre os tratamentos (Tabela 2). Na seqüência, o teste de Scott-Knott apontou que o progresso da doença não diferiu entre os tratamentos alternativos biomassa cítrica, grãos de kefir e óleo essencial de $E$. citriodora e, quando comparados ao extrato bruto de E. citriodora e à testemunha, exibiram valores estatisticamente inferiores, evidenciando o progresso mais lento da doença. $\mathrm{O}$ tratamento com azoxistrobina + ciproconazole proporcionou valores de taxa inferior aos demais tratamentos, evidenciando o progresso mais lento da doença.

Com relação à produtividade de grãos e ao peso de mil grãos, não foi constatado diferenças significativas entre os tratamentos, a nível de 5\% de probabilidade pelo teste $\mathrm{F}$ da ANOVA. Isso permite inferir que, neste ensaio, apesar dos diferentes níveis de intensidade de doença verificados entre os tratamentos, não houve implicações no rendimento de grãos (Tabela 2). Resultados semelhantes, com diferentes níveis de doenças entre tratamentos e a não-constatação de danos no rendimento de grãos em virtude da doença também foram apresentados por Reis et al. (12), trabalhando com diferentes fungicidas e doses para o controle da ferrugem asiática. Neste ensaio, possivelmente, a não-constatação de diferenças significativas para rendimento esteja relacionada ao fato dos primeiros sintomas da doença ter sido verificado apenas em R5, não havendo tempo suficiente para que a severidade provocasse danos de rendimento. A utilização de métodos alternativos dificilmente irá substituir por completo o uso de fungicidas tradicionais, mas pode contribuir para o controle integrado de doenças de plantas.

\section{REFERÊNCIAS BIBLIOGRÁFICAS}

1. Bergamin Filho, A. Curvas de progresso da doença. In: Bergamin Filho, A.; Kimati, H. \& Amorim, L. (Ed.) Manual de fitopatologia: princípios e conceitos. 3. ed. São Paulo: Agronômica Ceres, 1995. v.1, p.602-626.
2. Bettiol, W.; Tratch, R.; Galvão, J.A.H. Controle de doenças de plantas com biofertilizantes. Circular Técnica, Centro Nacional de Pesquisa do Meio Ambiente. Embrapa, Jaguariúna, n.2, p.1-22, 1997.

3. Campbell, C.L.; Madden, L. Introduction to plant disease epidemiology. New York: Wiley, 1990.

4. Costa, M.J.N.; Zambolim, L.; Rodrigues, F.A. Avaliação de produtos alternativos no controle da ferrugem do cafeeiro. Fitopatologia Brasileira, Brasília, v.32,n.2, p.150-155, 2007.

5. Empresa Brasileira de Pesquisa e Agropecuária. Prejuízo com ferrugem da soja se mantém estável nesta safra. Disponível em: 〈http://www.cnpso.embrapa.br/alerta/>. Acesso em: 4 jul.2008.

6. Ferreira, D.F. Sistema de análises de variância para dados balanceados. (SISVAR 4.1 pacote computacional). Lavras: UFLA, 2000

8. Godoy, C.V; Koga, L.J; Canteri, M.G. Diagrammatic scale for assessment of soybean rust severity. Fitopatologia Brasileira, Brasília, v. 31, n. 1, p. 63-68, 2006.

9. Instituto Brasileiro de Geografia e Estatística (IBGE). Milho e soja fazem Brasil ter produção recorde de grãos em 2007. Disponível em: http://www.ibge.gov.br/home/presidencia/noticias Acesso em: 6 jul.2010.

10. Medice, R.; Alves, E.; Assis, R.T; Magno Júnior, R.G..; Lopes, E.A.G.L. Óleos essenciais no controle da ferrugem asiática da soja Phakopsora pachyrhizi Syd. \& P. Syd. Ciência e Agrotecnologia, Lavras, v.31, n.1, p.83-90, 2007.

11. Piccinin, E.; Di Piero, R.M.; Pascholati, S.F. Efeito de Saccharomyces cerevisiae na produtividade de sorgo e na severidade de doenças foliares no campo. Fitopatologia Brasileira, Brasília, v. 30, n.1, p.5-9, 2005.

12. Reis, E.M.; Lima Neto, V.C; Godoy, C.V; Rosa, C.T; Castanho, H.E. Controle químico da ferrugem asiática da soja na região sul do Paraná. Scientia Agraria, Curitiba, v. 8, n.3, p. 25, 2007.

13. SAS Institute. SAS/STAT user's guide. 4ed. Cary, 1989.

14. Santos, F.S; Souza, P.E; Resende, M.L.V.; Pozza, E.A.; Miranda, J.C.; Ribeiro Júnior, P.M.; Manerba, F.C. Efeito de extratos vegetais no progresso de doenças foliares do cafeeiro orgânico. Fitopatologia Brasileira, Brasília, v.32, n.1, p.59-63, 2007.

15. Schwan-Estrada, K.R.F.; Stangarlin, J.R.; Cruz, M.E.S. Uso de plantas medicinais no controle de doenças de plantas. Fitopatologia Brasileira, Fortaleza, v. 28, Supl., p. 54- 56, 2003.

16. Tsukahara, R.Y.; Hikishima, M.; Canteri, M.G. Relações entre o clima e o progresso da ferrugem asiática (Phakopsora pachyrhizi) em duas micro-regiões do Estado do Paraná. Semina. Ciências Agrárias, Londrina, v. 29, p. 47-52, 2008.

17. Yorinori, J.T.; Paiva, W.M.; Frederick, R.D.; Fernandez, P.F.T. Ferrugem da soja (Phakopsora pachyrhizi) no Brasil e no Paraguai, nas safras 2000/01 e 2001/02. In: Congresso Brasileiro de Soja, Mercosoja 2002, Foz do Iguaçu, Resumos. Londrina: Embrapa Soja, 2002, p.94. (Embrapa Soja. Documentos, 181). 